\title{
Satisfaction of Health Care Users with the Quality of Health Care Services in Senegal: A Multi-Level Approach
}

\author{
Ndiack Fall \\ Faculty of Economics and Management (FASEG), University Cheikh Anta DIOP of Dakar (UCAD), Dakar, Republic of Senegal \\ Email: ndiackfall@gmail.com
}

How to cite this paper: Fall, N. (2017) Satisfaction of Health Care Users with the Quality of Health Care Services in Senegal: A Multi-Level Approach. Modern Econo$m y, 8,1135-1149$.

https://doi.org/10.4236/me.2017.89079

Received: August 23, 2017

Accepted: September 25, 2017

Published: September 28, 2017

Copyright $\odot 2017$ by author and Scientific Research Publishing Inc. This work is licensed under the Creative Commons Attribution International License (CC BY 4.0).

http://creativecommons.org/licenses/by/4.0/

\section{c) (i) Open Access}

\begin{abstract}
This paper analyzes the satisfaction of health care users with the quality of health care in the different types of health facilities in Senegal. The data used come from a survey of the Senegalese health system. In this framework, the multi-level approach with three levels of aggregation was used: patients (level 1), health facilities (level 2) and 14 administrative regions (level 3). The estimation results indicate a diversity, on the one hand, between regions, and on the other hand between health facilities. In addition, the individual characteristics of the patients have diverse effects across the levels of aggregation: the significance of most of them differs with respect to the context (e.g., gender, education level, age, smoking status and ownership of health insurance). While the waiting time and the applied rate effects differ slightly in terms of significance, the former influences negatively the satisfaction when waiting time is less than the duration of an appointment of the following day, whereas the level of satisfaction increases with the rate applied on health care.
\end{abstract}

\section{Keywords}

Patients, Quality of Health Care, Satisfaction, Levels of Aggregation, Multilevel Analysis

\section{Problem Statement}

Analyzing satisfaction is crucial to enable the beneficiaries of public services to adjudicate on the functioning of State's affairs, like a client having aspirations and choices in front of different goods and services supplied by a private firm [1].

Should users' opinion in general, and that of patients in particular, not be 
taken into account in the formulation of policies and strategies in order to achieve the objectives related to health? For a long time considered as less important for the improvement of the quality of health care, patients' opinion on the supply of health services is becoming essential in recent years [2] [3]. This trend is justified by the adoption of the new guidelines for universal health coverage $^{1}$ (UHC). This must go together with concrete and convincing results in order to coincide the needs with the supply of health care services in an environment where the patient has access to information on the nature and the quality of health care.

In Senegal, strategies were already in place to support certain vulnerable segments of the population to cover healthcare costs. Policy-makers have initiated health policies aiming to promote "health for all" concretizing the Alma-Ata Declaration of 1978, which put emphasis on access to basic health care services. The UHC that is an ambitious goal requires the access to health services and the protection against financial risk of the vulnerable social groups. The World Health Organization [4] defines UHC as a situation at national level characterized by an optimal use of resources to ensure the access for all to quality health care and to ensure a protection against poverty.

In this context, patient satisfaction was an essential aspect and its analysis deserves to be refined. What are the dimensions to consider in explaining patient satisfaction? What are the individual characteristics of the patients and those of the health care services and facilities, which determine the level of satisfaction? Many studies have investigated these questions [2] [5] [6].

These last years, particular emphasis has been put on finding a possible link between the environmental characteristics of health facilities and the level of patient satisfaction. This is mainly for these researches to grasp variation in patient satisfaction with regards to the context defined by hospitals [6] [7].

The latter concern is the focus of this paper. It is particularly important to understand the possible relationship between patient satisfaction with the quality of health care services and the context in which they receive health care. Thus, the first phase of the analysis of satisfaction is assumed and is not included in the methodological approaches considered in this paper. Therefore, the aim is to test the validity of the hypothesis on the variability of perception in relation to the environment defined by health facilities.

Two concepts are often used to refer to the person who uses health services: "patient" and "user". The first concept refers to the person who obviously uses health care services. The patient is the actual entity that is examined by health professionals. The user can be anyone who benefits from the available services in the health facilities; the patient may be a simple visitor, or parents and relatives of the patient.

The problem of distinguishing between these two concepts also arises in the hospital setting. The issue is of particular importance. Indeed, the sick person ${ }^{1}$ This refers to Universal Health Coverage (CMU) in the context of Senegal. 
does not often come alone to health professionals. His close relatives usually go together with him, they ask for information from the nursing staff. They can also benefit from services such as sanitary facilities, meals, etc. In addition, they are often the respondents in inpatient surveys. The patient may be in a situation that does not allow him to answer the questions (for example old people, and very young children), and people who are at his bedside answer on his behalf. But the patient is the subject that consults with health professionals. Thus, within the frame of medical satisfaction surveys, it is hard to establish a clear boundary between the concepts of "patient" and "user". As such, the two concepts are equivalent when one or the other can correctly give the opinion of the person subject to health care.

The analysis of user satisfaction started since long. A number of authors have attempted to define the concept of patient satisfaction in a relatively more or less direct way [8] [9] [10] [11]. Pascoe [12] formulated a fairly simple and pragmatic apprehension that "patient satisfaction would be defined as his reaction to his personal experience in services."

The WHO places a high priority on patient satisfaction. Indeed, the WHO considers patient satisfaction as an ultimate goal, placing this at the heart of the assessment of the quality of care. In this sense it considers that: "quality assessment is an approach which guarantees each patient diagnostic and therapeutic procedures that ensure the best health outcome in accordance with the current state of medical science, at the best cost, for the best result in the least iatrogenic risk and for greater satisfaction in terms of procedures, results and human contacts within the healthcare system...”.

The assessment of the quality of health care falls within a framework such that the patient-health professional relationship can be assimilated to the principal-agent model in contract theory [13]. Indeed, the asymmetry of information at the level of the patient on the quality of the services which he demands places him in position of the principal. The professional, who is not obliged to disclose his qualifications, may be considered as the agent. In this situation, the patient does not have a priori information on the characteristics of the health care professional and on care services in order to maximize his satisfaction. However, if the patient had complete information, his behavior would be similar to that of a consumer making the best choice [14]. In the absence of this advantage, he merely expresses, unfortunately or fortunately, his choice through approval or denunciation after using the services.

\section{Methodology: Multilevel Model}

Like social, economic and psychological phenomena, there are several methods of analyzing patient satisfaction based on individual characteristics. These different methods are based on statistical tools ranging from the simplest (chi-square independence test) to the more complex ones (econometric models). The former are less useful once the framework of the analysis exceeds two variables or the 
number of modality of the variables is high. The latter overcomes this difficulty; however, they are poorly adapted to explain the phenomenon when it comes to account for the context in which the individuals live [15]. These methods have many shortcomings.

The econometric models generally used to explain a phenomenon measured by a categorical variable belong to the field of the econometrics of qualitative variables. To consider the impact of the patient group, for instance the hospital environment, on the level of satisfaction, several models can be used such as linear regression and logistic regression ${ }^{2}$. However, the conclusions drawn from the studies using these models are biased, and the bias is greater if the intra group variability exceeds the intergroup variability [16]. To account for the group effect-for example, region, hospital or place of residence-in the analysis, classical approaches consist either in building models at each level of aggregation or to include in the individual model a group variable. The latter approach assumes that the influence of the group is identical for all individuals belonging to the same group.

The interest of multilevel models is at this level. They are used to find correlations between, on the one hand individual indicators and on the other hand socio-economic and demographic factors considered simultaneously at different levels: individual, health facility, locality, region, etc. Therefore, these methods allow analyzing the extent to which the environment affects the statistical links observed at the individual level. Let us present, first, the data before specifying the model and its hypotheses.

\subsection{Presentation of Data}

The data used were collected according to a plan inspired by the quota method. The database contains 2122 observations hierarchized in several levels of aggregation, from the smallest to the largest: individual level, health facility up to regional level. The target population consists of all inpatients and outpatients (but that are receiving health care at the time of the survey). The distribution of individuals by selected characteristics is presented in Table 1 .

Two variables related to patient satisfaction are included in the analysis: the technical quality of health care and the competence of the staff. They both have five modalities as shown in Table 2. These two variables are analyzed using multidimensional factor analysis (hierarchical clustering) in order to find a global and unique variable that is then considered as the dependent variable (Table 2).

Then, the latter can be transformed into a continuous variable by constructing a score function which consists of the coordinates on the first factorial axis of a discriminant analysis on this group variable. This procedure resulted in a more valid scale (which is more than $54 \%$ of the total variability) and more reliable with an alpha coefficient of Cronbach of over 0.77 , underlining the internal consistency of this measure. The choice of this new measure as dependent variable${ }^{2}$ Alker (1969), Baccaïni and Courgeau (1996a) cited by Courgeau et al. (1997). 
Table 1. Definition of data at three levels: individual, health facility and region.

\begin{tabular}{|c|c|}
\hline \multicolumn{2}{|c|}{ Level 1: patients $(\mathrm{n}=2122)$} \\
\hline \multicolumn{2}{|c|}{ Characteristics of patients } \\
\hline Age (less than 35) & $64.50 \%$ \\
\hline Sex (female) & $63.20 \%$ \\
\hline Education (none) & $57.50 \%$ \\
\hline Alphabetization (alphabetized) & $53.40 \%$ \\
\hline Residence (urban) & $45.10 \%$ \\
\hline Monthly income (less than 100,000 FCFA) & $69.30 \%$ \\
\hline Type of consultation (hospitalized) & $55.50 \%$ \\
\hline Smoking status (non-smoking) & $95.10 \%$ \\
\hline Health insurance (no) & $85.70 \%$ \\
\hline \multicolumn{2}{|c|}{ Level 2: health facility $(\mathrm{n}=219)$} \\
\hline \multicolumn{2}{|c|}{ Characteristics of health facilities } \\
\hline Type of health facility frequented (hospitals) & $48.90 \%$ \\
\hline Status of structure frequented (public) & $90.30 \%$ \\
\hline Average waiting time(minutes) & 42.4 \\
\hline Average applied rate (thousands of FCFA) & 23.1 \\
\hline Level 3: region (n & \\
\hline
\end{tabular}

Source: Authors' calculations based on survey data (2015).

Table 2. Description of variables capturing the satisfaction.

\begin{tabular}{ccc}
\hline \multirow{2}{*}{ Modalities } & Quality of care & Quality of staff \\
\cline { 2 - 3 } & $(\%)$ & $(\%)$ \\
\hline Very good & 12.87 & 23.09 \\
Good & 71.49 & 64.84 \\
Fairly good & 13.2 & 10.56 \\
Somewhat good much good & 1.93 & 1.04 \\
Not good at all & 0.52 & 0.47 \\
\hline
\end{tabular}

Source: Authors' calculations based on survey data.

which is very common [3] [17] - is justified by the fact that the estimated coefficients will have a direct and easy interpretation on a continuous scale of perception.

\subsection{Specification of the Multilevel Model}

Using the notations of the previous section and considering the individual level, 
the model for a patient $i$ of the structure $j$ in region $k$ can be specified as follows:

Level 1 (patients): $f\left(y_{i j k}\right)=\beta_{0}+X_{i j k} \beta+\varepsilon_{i}$

where $\beta_{0}$ is a scalar and $\beta=\left(\beta_{1}, \beta_{2}, \cdots, \beta_{H}\right)^{\mathrm{T}}$ the vector of parameters to be estimated, $X_{i j k}=\left(x_{i j k}^{1}, x_{i j k}^{2}, \cdots, x_{i j k}^{H}\right)$ refers to the vector of characteristics (explanatory variables).

If we restrict ourselves to this first level, this equation assumes that the parameters $\beta_{0}$ and $\beta$ do not vary from one structure to another, or from one region to another, and therefore the error term is of constant variance whatever the level considered. This is a strong hypothesis according to the development of the previous section. The advantage of using multilevel models is to remove this hypothesis by assuming that these coefficients, which measure the effects of the variables $X$, may vary with respect to the aggregation levels. Therefore, we have the system of equations for the health structure $j$ :

Level 2 (health facilities): $\left\{\begin{array}{l}\beta_{0 j}=\gamma_{00}+z_{j} \gamma_{01}+u_{0 j} \\ \beta_{j}^{t}=\gamma_{0}+z_{j} \gamma_{1}+u_{j}\end{array}, j\right.$ indicating the structure.

In this system, the variables $z$, measured at level 2 , are identical for all patients belonging to a given level $j$. They represent the specific effects of health facilities on the parameters.

The introduction of a third level relaxes the constraint on the coefficients $\gamma$ which are no longer considered as constants. Consequently, these coefficients are liable to vary between the clusters of the third level (regions), possibly as a function of new variables $w$, and we obtain the following system of equations for the region $k$ :

Level 3 (regions): $\left\{\begin{array}{l}\gamma_{0 l k}=\rho_{0 l}+w_{k} \rho_{011}+r_{0 l k} \\ \gamma_{l k}^{t}=\rho_{01 l}+w_{k} \rho_{1 l}+r_{l k}\end{array}, l=0.1\right.$

To summarize, we denote:

$j$ : index of level 2 (health facilities)

$k$ : index of level 3 (regions)

l: is equal to 0 (respectively 1 ) indicating the constant (respectively the slope) in the equations of level 2

$\mathrm{H}$ : number of explanatory variables;

$z$ : variable measured at level 2, is constant for all patients of the structure $j$

$w$ : variable measured at level 3, is constant for all entities of a given region $k$.

The error terms $\varepsilon, \mathrm{u}$ and $\mathrm{r}$ are independently and identically distributed of mean zero and following the normal distribution.

The above equations are expressed in their general form; we could have a simplified specification by considering that the variables $w_{k}$ and $z_{j}$ are not observed or are unobservable. Therefore their effects are integrated into the error terms $r$ and $u$, respectively. Hence, the last two systems are specified as follows:

Level 2: $\left\{\begin{array}{l}\beta_{0 j}=\gamma_{0}+u_{0 j} \\ \beta_{j}=\gamma+u_{j}\end{array}\right.$ and level 3: $\left\{\begin{array}{l}\gamma_{0 l k}=\rho_{0}+r_{0 k} \\ \gamma_{l k}=\rho+r_{k}\end{array}\right.$

In multilevel analysis, the analysis of the variances and covariance of the error 
terms constitutes the essential tools to understand the variability between the different levels of aggregation. For this purpose, it is sufficient to specify the final model as a function of the expressed parameters in the systems of levels 2 and 3; this leads to make substitutions of the different parameters intervening at each level, then grouping the random and the deterministic terms. Thus, the following equation is obtained:

$$
f\left(y_{i j k}\right)=\gamma_{0}+r_{0 k}+u_{0 j}+X_{i j k}\left(\gamma+r_{k}+u_{j}\right)+\varepsilon_{i}
$$

Which can also be expressed in the form:

$$
f\left(y_{i j k}\right)=\left(\gamma_{0}+X_{i j k} \gamma\right)+\left[r_{0 k}+u_{0 j}+X_{i j k}\left(r_{k}+u_{j}\right)+\varepsilon_{i}\right]
$$

Thus, the latter equation is the sum of a deterministic term (first term) and a random term (second term). By calculating the member-to-member variance, and under the assumption that the random terms at the three different levels are independent of each other, we have:

$$
\begin{aligned}
V\left[f^{\prime}\left(y_{i j k}\right)\right]= & \sigma_{r_{0}}^{2}+\sigma_{u_{0}}^{2}+\sigma_{\varepsilon}^{2}+X_{i j k}[V(r)+V(u)] X_{i j k}^{t} \\
& +2 X_{i j k} \operatorname{cov}\left(u_{0}, u\right)+2 X_{i j k} \operatorname{cov}\left(r_{0}, r\right)(*)
\end{aligned}
$$

The relation $(*)$ helps to interpret the results of the estimation. Thus, the total variability of the variable of interest-here the satisfaction score-is broken down into four parts: variability due to unobserved/unobservable phenomena at all three levels, variability due to individual characteristics, and variability induced by fluctuations in the specific effects of these characteristics between health facilities on the one hand, and between regions on the other. The last two terms reflect the correlation between the coefficients associated to the variables (slopes) and the average scores at the two aggregation levels.

Some common hypotheses in the linear model are neglected in multilevel modeling. However, since the estimation is done by maximum likelihood, the independence and normality of the error terms at each level are assumed. However, the normality of errors is not restrictive with a large sample [18]. Moreover, the fundamental hypothesis is that the multi-level model is different from linear regression. In this framework, a test based on the Wald statistic is used as a guide for the comparison of these two models.

\section{Analysis and Interpretation of Results}

This section presents and analyzes the results of the modeling after providing some descriptive statistics of the variables.

\subsection{Descriptive Analysis and Satisfaction Profile}

The satisfaction profile depends on the level of analysis.

\subsubsection{Satisfaction Profile by Patient Characteristics}

Table 3 shows some similarities in the patient satisfaction profile with respect to individual characteristics: almost, regardless of the sub-category considered, the satisfaction rates are similar. 
Table 3. Patient satisfaction profile.

\begin{tabular}{|c|c|c|c|c|}
\hline \multirow{2}{*}{\multicolumn{2}{|c|}{ Characteristics of patients }} & \multicolumn{3}{|c|}{ Level of satisfaction of patients } \\
\hline & & Not good (\%) & Good (\%) & Very good (\%) \\
\hline \multirow{6}{*}{ Age } & Less than 5 & 18.3 & 55.3 & 26.4 \\
\hline & Between 5 and 17 & 18.3 & 59.3 & 22.3 \\
\hline & Between 18 and 34 & 15.9 & 58.3 & 25.7 \\
\hline & Between 35 and 64 & 18.5 & 55.7 & 25.9 \\
\hline & Between 65 and 74 & 16.3 & 51.9 & 31.9 \\
\hline & 75 and more & 22.6 & 50.0 & 27.4 \\
\hline \multirow{2}{*}{ Sex } & Male & 17.3 & 55.8 & 26.9 \\
\hline & Female & 17.6 & 57.2 & 25.2 \\
\hline \multirow{4}{*}{ Income } & Less than 50,000 & 14.6 & 65.4 & 20.0 \\
\hline & $50,000-100,000$ & 21.1 & 50.1 & 28.9 \\
\hline & $100,000-200,000$ & 18.5 & 51.3 & 30.2 \\
\hline & More than 200,000 & 15.0 & 55.6 & 29.4 \\
\hline \multirow{2}{*}{ Health insurance } & Yes & 20.7 & 55.6 & 23.7 \\
\hline & No & 16.9 & 56.9 & 26.2 \\
\hline \multirow{3}{*}{ Milieu of residence } & Urban & 13.1 & 59.3 & 27.7 \\
\hline & Suburban & 32.4 & 48.8 & 18.8 \\
\hline & Rural & 15.5 & 57.5 & 27.1 \\
\hline \multirow{2}{*}{ Smoking status } & Smoker & 10.5 & 51.4 & 38.1 \\
\hline & Non-smoker & 17.9 & 57.0 & 25.2 \\
\hline \multirow{4}{*}{ Education level } & None & 18.7 & 56.4 & 24.9 \\
\hline & Primary & 16.5 & 57.4 & 26.1 \\
\hline & Secondary & 14.9 & 57.7 & 27.4 \\
\hline & Superior & 16.2 & 53.3 & 30.5 \\
\hline \multirow{2}{*}{ Type of hospitalization } & Hospitalization & 16.7 & 54.3 & 29.0 \\
\hline & External consultation & 18.4 & 59.7 & 21.9 \\
\hline
\end{tabular}

Source: Authors' calculations based on survey data.

The perception rate varies between $14 \%$ and $21 \%$ for the lowest level of satisfaction "not good", between $50 \%$ and $60 \%$ for the "good" level, and between $20 \%$ and $30 \%$ for the highest level of satisfaction "very good". The conclusion is that the satisfaction rate is generally high in all profiles (whether male or female, young or adult, less educated or even literate or not, etc.). However, it should be noted that smoking patients are relatively the most likely to have excellent satisfaction with the technical quality and competence of health professionals. In fact, $38 \%$ of this group of patients believe, that the quality of health services is very good. This slight difference is also seen for patients aged between 65 and 74 (32\% say that the quality of care and medical staff is very good), and those with a monthly income between 100,000 and 200,000 (30\%), and patients with university 
education (31\%). On the other hand, people over 74 years old are relatively more likely to have a negative perception of quality of care (22\% in all senior patients).

\subsubsection{Satisfaction Profile by Health Facility Characteristics}

The analysis according to the characteristics of the health facilities is summarized in Table 4. The key points are that waiting times in health facilities decline, on average, with patient satisfaction. Indeed, the average waiting time amounts to 60 minutes for patients with negative perception, 41 minutes for those with good perception and 33 minutes for patients with very good satisfaction.

Conversely, the rate applied increases, on average, with the level of satisfaction, ranging from 18,800 CFA F (for the dissatisfied), to 20,200 for those who appreciate well the quality of care and to 32,000 for those having a very good level of satisfaction. The findings indicate that patients who attend private health facilities have generally a very positive perception of the quality of care they receive (33.5\%). In addition, $20.5 \%$ of patients who go to hospitals are less satisfied. Nevertheless, the conclusions remain the same: the satisfaction rates are high exceeding $50 \%$.

\subsubsection{Satisfaction Profile by Regions}

The analysis of patient satisfaction in the 14 regions is based on Table 5, suggesting a number of comments. Patients living in the Diourbel region are relatively more likely to have a negative perception of the quality of health services and care (35.78\%), followed by the regions of Matam (32.39\%) and Thiès (28.33\%). Nonetheless, the regions of Ziguinchor, Kolda, Kaolack, Fatick and Sédhiou have the lowest negation perception rates (barely $8 \%$ ). Correlatively, it is in these same latter regions that the highest rates of very good satisfaction are recorded. For instance, in the Fatick and Ziguinchor regions, 35.7\% of patients were very satisfied with the quality of health care.

Table 4. Satisfaction profile by health facility characteristics.

\begin{tabular}{|c|c|c|c|c|}
\hline \multirow{2}{*}{\multicolumn{2}{|c|}{ Quantitative characteristics (averages) }} & \multicolumn{3}{|c|}{ Level of satisfaction of patients } \\
\hline & & Not good & Good & Very good \\
\hline Rate applied & (Thousands of FCFA) & 18.9 & 20.2 & 32.2 \\
\hline Waiting time & (minute) & 60.3 & 41.4 & 32.5 \\
\hline \multicolumn{2}{|c|}{ Qualitative characteristics(in percentage) } & Not good & Good & Very good \\
\hline \multirow{3}{*}{ Type de structure } & Hospitals (\%) & 20.5 & 52.5 & 27 \\
\hline & Health Center (\%) & 15.3 & 58.5 & 26.2 \\
\hline & Health Post (\%) & 13.4 & 64.5 & 22.2 \\
\hline \multirow{2}{*}{ Status of structure } & Public (\%) & 18 & 57.1 & 25 \\
\hline & Private (\%) & 13.1 & 53.4 & 33.5 \\
\hline \multicolumn{2}{|c|}{ Total (\%) } & 17.48 & 56.7 & 25.8 \\
\hline
\end{tabular}

Source: Authors' calculations based on survey data. 
Table 5. Analysis of patient satisfaction by regions.

\begin{tabular}{cccc}
\hline \multirow{2}{*}{ Region } & \multicolumn{3}{c}{ Level of satisfaction of patients } \\
\cline { 2 - 4 } Dakar & Not good & Good & Very good \\
Dioubdel & 15.0 & 58.2 & 26.8 \\
Fatick & 35.8 & 49.0 & 15.2 \\
Kaffrine & 7.1 & 57.1 & 35.7 \\
Kaolack & 17.4 & 55.8 & 26.7 \\
Kolda & 5.7 & 66.4 & 27.9 \\
Kedougou & 5.2 & 67.0 & 27.8 \\
Louga & 18.2 & 81.8 & 00.0 \\
Matam & 15.1 & 53.8 & 31.1 \\
Saint-louis & 32.4 & 46.5 & 21.1 \\
Sédhiou & 19.1 & 50.3 & 30.6 \\
Tambacounda & 8.1 & 60.8 & 31.1 \\
Thiès & 17.7 & 61.2 & 21.2 \\
Ziguinchor & 28.3 & 52.5 & 19.2 \\
Total & 4.8 & 59.5 & 35.7 \\
\hline
\end{tabular}

Source: Authors' calculations based on survey data.

One notable fact is that in Kédougou, patients do not have a very good level of satisfaction although nearly $82 \%$ think that the quality of health care is only good.

\subsection{Results of Multi-Level Modeling}

Two models are considered: the first consists in regressing the satisfaction score without including the regressors (without the socio-demographic characteristics of the patients and the characteristics of the health facilities), and the second model measures the residual variance explained at the different levels of aggregation after taking into account in the model the characteristics of the patients and those of the health facilities.

\subsubsection{Model without Explanatory Variables}

Table 6 shows that disparities in satisfaction between health facilities on the one hand and between regions on the other hand are statistically significant. Therefore, these two levels of aggregation have significant impacts on the variability in the level of patient satisfaction.

\subsubsection{Model with Explanatory Variables: Fixed Part (Effect of Patient Characteristics)}

Table 7 presents the results of the estimation which includes the individual characteristics of the patients under the assumption that the variables $w$ and $z$, 
Table 6. Model without explanatory variables.

\begin{tabular}{rccc}
\hline Effects of random parameters & Variance & Standard error & t Statistic \\
\hline Region: $\sigma_{r_{0}}^{2}$ & $0.4056^{* *}$ & 0.1052 & 3.86 \\
Health structures: $\sigma_{u_{0}}^{2}$ & $0.5677^{* * *}$ & 0.0537 & 10.57 \\
Patients: $\sigma_{\varepsilon}^{2}$ & $1.3624^{* * *}$ & 0.0218 & 62.50 \\
\hline
\end{tabular}

Source: Authors based on survey data Significance: $\left(^{*}\right) 10 \% ;\left({ }^{* *}\right) 5 \% ;\left({ }^{* *}\right) 1 \%$.

Table 7. Model with explanatory variables.

\begin{tabular}{|c|c|c|c|}
\hline Variables & Coefficients & Standard errors & $\mathrm{P}>\mathrm{Z}$ \\
\hline Age (less than de 34) & -0.009 & 0.024 & 0.713 \\
\hline Sex (female) & 0.013 & 0.065 & 0.839 \\
\hline \multicolumn{4}{|l|}{ Education level (none) } \\
\hline Primary & 0.067 & 0.078 & 0.393 \\
\hline Secondary & 0.072 & 0.087 & 0.408 \\
\hline Superior & 0.097 & 0.152 & 0.524 \\
\hline \multicolumn{4}{|l|}{ Milieu of residence (urban) } \\
\hline Suburban & $-0.466^{* * *}$ & 0.093 & 0.000 \\
\hline Rural & 0.083 & 0.082 & 0.316 \\
\hline Income & 0.059 & 0.074 & 0.422 \\
\hline \multicolumn{4}{|l|}{ Smoking status (smoker) } \\
\hline Non-smoker & -0.070 & 0.127 & 0.836 \\
\hline \multicolumn{4}{|l|}{ Health insurance (yes) } \\
\hline Non insured & $0.147^{\star}$ & 0.086 & 0.068 \\
\hline Applied rate & $1.0 \mathrm{E}-6^{\star *}$ & $4.9 \mathrm{E}-7$ & 0.041 \\
\hline Waiting time & $-0.002^{* * *}$ & $4.7 \mathrm{E}-4$ & 0.000 \\
\hline Waiting time squared & $8.5 \mathrm{E}-7^{\star \star *}$ & $2.6 \mathrm{E}-7$ & 0.004 \\
\hline
\end{tabular}

Source: Authors' calculations based on survey data Significance: $\left({ }^{*}\right) 10 \%$; $\left(^{* *}\right) 5 \%$; $\left(^{* * *}\right) 1 \%$.

mentioned above, are included in the error terms. The findings suggest that even at the $10 \%$ level of significance some characteristics of the patients are not significant: sex, age, income, type of consultation, smoking status, education level. Patients living in a suburban environment are found to have relatively a lower level of satisfaction than those living in urban areas. Similarly, patients without health insurance have, to a certain extent, a much better level of satisfaction than those with health insurance.

In addition, waiting time has a negative and significant impact on user satisfaction. An additional one unit of waiting time (one minute) leads to a decrease in the score of 0.002 points, hence deterioration in the level of satisfaction. However, this impact weakens when the waiting time exceeds 22.9 hours. Indeed, since the coefficient of the square of waiting time is positive and significant, a 
simple calculation enables to find the turning point of the effect of waiting time on satisfaction. This turning point corresponds, without any doubt, to the carry-forward time of the medical support.

In this context, patients who wait longer by appointment from their first contact with the physician have a level of satisfaction that is not necessarily affected by the postponement of health care. Figure 1 illustrates the evolution of the satisfaction score as a function of waiting time. The observation is that long waiting times are associated with higher values of the patient satisfaction score.

\subsubsection{Random Part: Effect of Aggregation Levels}

Table 8 reveals that the variability in patient perception is influenced by the context in which they receive health care. Indeed, the variances of the parameters at the two levels of aggregation are significant at the $5 \%$ level of significance.

The findings suggest that $41.1 \%$ of the variability due to aggregation levels is explained at the regional level, while $58.9 \%$ is explained at the level of the health facilities. According to these results, although health facility characteristics are not significant at the $5 \%$ level of significance, there is some diversity in patient satisfaction between health facilities on the one hand and the regions on the other. Indeed, the variance of the parameter $\gamma_{0}$ is significant. Similarly, at the regional level, a variance of the parameter $\rho_{0}$ is significant. The questions that obviously arise from these findings are to know what explains these variability's between these levels of aggregation. The analysis of the correlations allows understanding certain aspects (Table 9).

Table 9 presents the correlations between the effects of the variables (slopes) and average scores in health facilities. The variable nature of the effect of a variable on the score of satisfaction is appreciated based on these correlation coefficients. Thus, the impact of waiting time varies considerably and positively with the average level of satisfaction. Indeed, the coefficient of correlation between the effect of waiting time and the average score per structure is almost 1 . This result indicates that the higher the average score in a structure is, the more the score of the patient depends highly on waiting time. In other words, more patients are satisfied with the quality of care in a health facility, more waiting time becomes inconvenient. This relationship between waiting time and score can

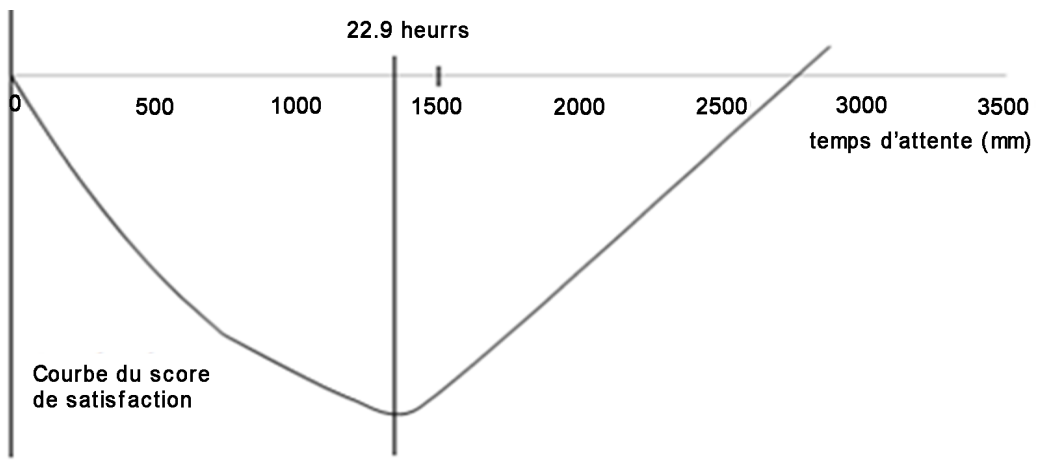

Figure 1. Evolution of satisfaction score in function of waiting time. Source: Authors' calculations based on survey data. 
Table 8. Effect of aggregation levels.

\begin{tabular}{cccc}
\hline Variables & Coefficients & Standard error & $P>Z$ \\
\hline Type of structure (Hospital) & & & \\
\hline Center of health & $0.155^{*}$ & 0.093 & 0.094 \\
Poste of health & 0.165 & 0.127 & 0.193 \\
Status of the structure (public) & & \\
Private & $0.285^{* *}$ & 0.132 & 0.031 \\
\hline Effect of random parameters & & Estimated value & Standard error \\
\hline Region: $\sigma_{r_{0}}^{2}$ & $0.365^{* * *}$ & 0.101 \\
Health facility: $\sigma_{u_{0}}^{2}$ & & $0.523^{* * *}$ & 0.053 \\
Individual: $\sigma_{\varepsilon}^{2}$ & & $1.348^{* * *}$ & 0.022 \\
\hline
\end{tabular}

Source: Calculation of authors using CREA (2015) data Significance: $\left(^{*}\right) 10 \%$; $\left(^{* *}\right) 5 \%$; $\left(^{* * *}\right) 1 \%$.

Table 9. Analysis of relative specific effects of variables.

\begin{tabular}{|c|c|c|c|c|}
\hline \multirow{2}{*}{ Variables } & \multicolumn{2}{|c|}{ Health structure } & \multicolumn{2}{|c|}{ Regions } \\
\hline & Covariance & T statistic & Covariance & $\mathrm{T}$ statistic \\
\hline Age & 0.0845 & 0.008 & $0.0147^{\star *}$ & 1.766 \\
\hline Sex & 0.1424 & 0.070 & 0.0047 & 0.760 \\
\hline Level of education & 0.1398 & 0.031 & 0.0134 & 1.879 \\
\hline Milieu of residence & $0.5489^{* * *}$ & 2.842 & -0.2132 & -0.454 \\
\hline Income & $0.2186^{* * *}$ & 3.503 & $-0.1282^{\star}$ & -1.301 \\
\hline Smoking status & $0.2765^{\star * *}$ & 4.993 & $0.0114^{*}$ & 1.513 \\
\hline Health insurance & $0.2806^{* * *}$ & 4.988 & $0.0129^{*}$ & 1.608 \\
\hline Applied rate & 0.0000 & 0.000 & 0.0000 & 0.000 \\
\hline Waiting rate & $0.0000^{\star *}$ & 2.007 & $0.0000^{* *}$ & 2.013 \\
\hline Type de structure & $0.1368^{\star *}$ & 1.645 & $0.0267^{\star *}$ & 1.973 \\
\hline Status of the structure & 0.0507 & 0.218 & $0.0242^{*}$ & 1.612 \\
\hline
\end{tabular}

Source: Author based on survey data. Significance: $\left(^{*}\right) 10 \% ;\left(^{* *}\right) 5 \% ;\left({ }^{* * *}\right) 1 \%$.

become inconvenient. This relationship between waiting time and score can be easily interpreted: the better the quality of care of a health facility is, the larger the influx in the structure is, and therefore waiting time increases and affects negatively patient satisfaction.

Thus, the main lessons learned from Table 9 are that the effect of a variable on the level of satisfaction may vary from one health facility to another. Other variables, although not significant at the $5 \%$ significance level, still have potential effects that vary significantly from one health facility to another. For instance, income, health insurance, gender, smoking status, educational attainment and place of residence, could have significant effects if one group of health facilities was considered instead of another. 
This also holds when it comes to regional level. The variables: age, income, smoking status, health insurance, applied rate and waiting time have specific effects that vary from one region to another.

\section{Conclusions}

Taking into account the different levels of aggregation, it leads to the improvement in the analysis of patient satisfaction with respect to the quality of health care services. Indeed, the contextual effect is remarkable in patients' assessment of health care and is expressed in both direct and indirect ways. The direct path corresponds to the fact that the average score (average level) of patient satisfaction is markedly different when moving from one health facility to another, or from one region to another. As a result, patients tend to have a relatively higher or lower level of satisfaction in a given level of aggregation. In contrast, the indirect path induces differentiated effects for the explanatory variables at the different levels of aggregation. In this case, the effect of the context "modifies" the relationship between individual characteristics of patients and the level of perception.

In some cases, even if a variable does not have a significant effect in a given health or geographic environment, it can have a significant effect once the environment changes. Therefore, not taking into account the existing hierarchy in the data would lead to vicious conclusions. The multi-level analysis helps to avoid this confusion by highlighting the fixed effects from one structure to another and the random effects due to the specificities of the health facilities (unobserved and unobservable phenomena such as managerial behavior of the head of department, etc.). However, the waiting time and the applied rate are two variables that have significant effects with relatively stable signs on patient satisfaction, these effects were also stable even after taking into account the diversity between health facilities; however, their magnitude may vary from one health facility to another.

\section{References}

[1] Ragaigne, A. (2010) Contrôler à distance la satisfaction des usagers des services publics locaux. [Remotely Monitor the Satisfaction of Users of Local Public Services.] Informations Sociales, 158, 68-75.

[2] Jha, A.K., et al. (2008) Patients' Perception of Hospital Care in the United States. New England Journal of Medicine, 359, 1921-1931. https://doi.org/10.1056/NEJMsa0804116

[3] Murante, A.M. (2010) Maria. Patient Satisfaction: A Strategic Tool for Health Services Management. Thèse de doctorat, Scuola Superiore Sant'Anna.

[4] WHO (2013) World Health Report 2013: Research for Universal Health Coverage. Number of pages: 168 Languages: English, Arabic, Chinese, French, Portuguese, Spanish, Russian.

[5] Westaway, M.S., Rheeder, P., Van Zyl, D.G. and Seager, J.R. (2003) Interpersonal and Organizational Dimensions of Patient Satisfaction: The Moderating Effects of Health Status. International Journal for Quality in Health Care, 15, 337-344. 
https://doi.org/10.1093/intqhc/mzg042

[6] Kollen, B.J., Groenier, K.H. and Berendsen, A.J. (2011) Patients' Experiences with Continuum of Care across Hospitals. A Multi Level Analysis of Consumer Quality Index Continuum of Care. Patient Education and Counseling, 83, 269-272. https://doi.org/10.1016/j.pec.2010.04.035

[7] Stubble, J.H., Brouwer, W. and Delnoij, D.M.J. (2007) Patients' Experiences with Quality of Hospital Care: The Consumer Quality Index Cataract Questionnaire. BMC Ophthalmology, 7, 14.

[8] Lebow, J.L. (1983) Research Assessing Consumer Satisfaction with Mental Health Treatment: A Review of Findings. Evaluation and Program Planning, 6, 211-236.

[9] Liu, S.S., Amendah, E., Chang, E.-C. and Pei, L.K. (2008) Satisfaction and Value: A Meta-Analysis in the Healthcare Context. Health Marketing Quarterly, 23, 49-73.

[10] Ijaouane, É. (2012) Évaluation de la satisfaction des soins en pédopsychiatrie par les enfants hospitalisés et par leurs parents. [Assessment of Patient's and Their Parents' Care Satisfaction in a Child Mental Healthinpatient Unit.] Thèse de L'Université JOSEPH FOURIER FACULTE DE MEDECINE DE GRENOBLE. Médecine humaine et pathologie.

[11] Susie, L.-P. (1982) Toward a Theory of Patient Satisfaction. Social Science \& Medicine, 16, 577-582. https://doi.org/10.1016/0277-9536(82)90311-2

[12] Pascoe, G.C. (1983) Patient Satisfaction in Primary Health Care: A Literature Review and Analysis. Evaluation and Program Planning, 6, 185-210.

[13] Rochaix, L. (1997) Asymétries d'information et incertitude en santé: les apports de la théorie des contrats. [Information Asymmetries and Uncertainty in Health: The Contributions of the Theory of Contracts.] Economie \& Prévision, 129, 11-24.

[14] Shackley, P. and Ryan, M. (1994) What Is the Role of the Consumer in Health Care? Journal of Social Policy, 23, 517-541. https://doi.org/10.1017/S0047279400023333

[15] Dinaucourt, M. (2002) Méthode d'analyse régionale sur données individuelles: Introduction aux modèles multi-niveaux. [Regional Analysis Method on Individual Data: Introduction to Multi-Level Models.]

[16] Courgeau, D. and Baccaïni, B. (1997) Analyse Multi-Niveaux en Sciences Sociales. Population (French Edition), 52, 831-863. https://doi.org/10.2307/1534616

[17] Brown, A.D., Sandoval, G.A., Murray, M. and Boissonnault, B. (2008) Comparing Patient Reports about Hospital Care across a Canadian-US Border. International Journal for Quality in Health Care, 20, 95-104. https://doi.org/10.1093/intqhc/mzm061

[18] Bonnieux, F. (1983) La démarche économétrique: Principes et difficultés illustrés à partir d'un exemple. [The Econometric Approach: Principles and Difficulties Illustrated in from an Example.] Économie rurale, 157, 35. 
Submit or recommend next manuscript to SCIRP and we will provide best service for you:

Accepting pre-submission inquiries through Email, Facebook, LinkedIn, Twitter, etc. A wide selection of journals (inclusive of 9 subjects, more than 200 journals)

Providing 24-hour high-quality service

User-friendly online submission system

Fair and swift peer-review system

Efficient typesetting and proofreading procedure

Display of the result of downloads and visits, as well as the number of cited articles Maximum dissemination of your research work

Submit your manuscript at: http://papersubmission.scirp.org/

Or contact me@scirp.org 